\title{
peripheria
}

vol.4, julio 2006

www.periferia.name

\section{Per una reflexió crítica sobre la noció de mestissatge}

\author{
M. Clua, A. Coello, M. Martínez Mauri, J.- LI. Mateo, J. Muela, M. Ojeda, \\ V.Stolcke i M. Ventura (AHCISP) - UAB ${ }^{1}$
}

\section{Resum}

A través d'una anàlisi històrica i transcultural de l'Europa cristiana, el món jueu, àrab-musulmà, subsaharià, indígena americà i crioll, el projecte actual busca explicar l'origen, el procés, els sentits, les justificacions socials i culturals i els usos contemporanis del concepte de "mestissatge", l'espai social de les barreges i els ponts culturals, per desenvolupar una proposta des de l'antropologia històrica d'anàlisi dels mestissatges com a categories i com a fenòmens socioculturals.

\begin{abstract}
Through a transcultural and historical analysis of Christian Europe, Jewish, ArabicMuslim, Subsaharian, American Indigenous and Creole Worlds, the current project is intended to explain the origin, process, meanings, social and cultural justifications and the current uses of "hybridation" concept. Also, the project tries to understand the social space and the barriers and cultural bridges for developing a proposal from the Historic Anthropology for these categories and those sociocultural phenomena.
\end{abstract}

\section{Perquè cal una crítica a la noció de mestissatge}

Davant l'explosió d'identitats particulars vinculades a una suposada homogeneïtzació cultural fruit del procés de mundialització, els mestissatges es proposen com a respostes socials i polítiques que haurien de permetre la integració i la convivència pacífica de persones d'orígens diferents que es troben en les societats complexes occidentals. Amb tot, la perspectiva del mestissatge i la seva corresponent problemàtica teòrica i social del sincretisme cultural, no evita els fonamentalismes identitaris, ja que el propi concepte implica una barreja d'elements originals substancialment diferents. Ara bé: aquesta noció, aplicada i difosa inicialment en la formació de l'Amèrica hispànica colonial, no representa un fenomen de vigència universal; ni en totes les societats ni en tots els moments històrics s'interpreten les transgressions de fronteres sociopolítiques com a "mescles". Cal aleshores una recerca històrica i transcultural sobre les condicions de

\footnotetext{
${ }^{1}$ Amb una perspectiva històrica i etnogràfica, I'L'AHCISP analitza els problemes antropològics derivats del dualisme cartesià natura-cultura (racismes, culturalismes, construcció social de l'entorn, de les identitats o el mestissatge amb una clara perspectiva de gènere). L'AHCISP (Antropologia i Història de la Construcció d'Identitats Socials i Polítiques), és un equip de recerca, amb ANE reconegut per la UAB el 2003. Està format per Montserrat Clua, Alexandre Coello, Mònica Martínez Mauri, Josep Lluis Mateo, Joan Muela, Maite Ojeda i coordinat per Verena Stolcke i Montserrat Ventura. Podeu enviar la correspondència a: Montserrat.Ventura@uab.es
} 


\section{peripheria \\ vol.4, julio 2006 \\ www.periferia.name}

possibilitat de la concepció i la percepció de mestissatges, així com del rol que cada societat atorga i/o ha atorgat a les mescles $\mathrm{i}$ als personatges que han exercit de ponts culturals, per a entendre el seu lloc en les respectives visions del món, en les ideologies culturals de cada societat, i desenvolupar una proposta des de l'antropologia històrica d'anàlisi dels mestissatges com a categories i com a fenòmens socioculturals.

\section{Antecedents}

Existeix una considerable literatura antropològica sobre processos socioculturals i polítics de formació i transformació d'identitats socioculturals. D'altra banda, des de I'antropologia també s'ha desenvolupat recentment l'estudi de les fronteres. Malgrat això, molt menys freqüent és l'estudi dels ponts i/o de les transgressions de fronteres socials i polítiques, així com de les seves conseqüències, és a dir, d'allò que genèricament podria anomenar-se "mescles". Des d'aquesta inquietud, els estudis previs dels membres de l'equip han servit per observar, analitzar i establir algunes de les condicions de producció dels "mestissatges" en diferents moments històrics i en diferents realitats culturals.

V. Stolcke ha dedicat la seva llarga carrera investigadora a l'estudi de la construcció política de les desigualtats socioeconòmiques en la seva intersecció amb estereotipus racials i valors sexuals així com les estructures de gènere a la Cuba colonial (1974) i en la transició de l'esclavitud al treball lliure en les plantacions de cafè de Sao Paulo, Brasil (1988, 1998b, 2002, 2003b). Ha estudiat tambén les noves retòriques culturalistes d'exclussió d'immigrants no europeus en la Unió Europea (1995, 2000a, 2000b, 2004a), la definició de la nacionalitat i la ciutadania com a fonament dels estats nacionals en l'Europa moderna (1997), així com el rerafons cartesià en els problemes identitaris i per a les relacions de parentiu convencionals i de gènere (2003a) que plantegen les noves tecnologies reproductives com a intervenció tecnològica en processos "naturals" com ho era la procreació (1988, 1998). Seguint amb la vessant teòrica d'anàlisi dels criteris utilitzats en la definició de la pertinença ètnica i nacional a través dels conceptes de nacionalitat i ciutadania, M.Clua ha analitzat el nacionalisme i les teories que s'han elaborat des de les ciències socials per aquestes formes polítiques modernes d'identitat de grup (1998). També ha estudiat la relació entre l'antropologia i el nacionalisme (2003) a través de l'anàlisi de les nocions que s'han construit des 


\section{peripheria \\ vol.4, julio 2006 \\ www.periferia.name}

d'ambdós discursos (el científic i el sociopolític) per explicar i justificar els criteris de pertinença/exclusió del grup (raça, ètnia, cultura, nació, nacionalitat...). A l'Amèrica Llatina, la producció de les identitats ha estat analitzada per a les terres baixes d'Amèrica del Sud per M. Ventura i Oller, qui després d'una anàlisi teòrica sobre les nocions d'etnicitat i racisme (1994) centra la seva recerca de camp sobre el grup indígena Tsachila de l'Equador tant en la seva particular construcció identitària (1997) como en el procés històric i dinàmic que l'ha contribuït a constituir (1995), especialment en els processos d'intercanvi amb altres grups ètnics que han configurat les seves representacions simbòliques (1999a, 1999b, 2000a, 2000b, 2003), així com un dels pilars d'aquesta recerca, el concepte de persona com a productor d'identitat (2001, 2002) o les relacions amb l'alteritat no humana (2004). Igualment per a l'Amèrica del Sud, la producció d'identitats i els primers mestissatges han estat analitzats per al món andí per A. Coello, qui ha assenyalat la relació entre el criollisme peruà i la mística del recolliment en la Companyia de Jesús en el s. XVII ( 2000, 2002a, 2002b, 2003); Més al nord, a Panamà, M. Martínez Mauri ha centrat els seus treballs en el grup indígena Kuna, analitzant la interacció entre els nous actors polítics (ONG indígenes) i les agències internacionals $(2003,2006)$. En les seves recerques ha analitzat les transformacions que provoquen els projectes de desenvolupament sobre les identitats i les representacions kunes del mediambient tenint en compte el rol dels mediadors culturals (2005, en premsa). Quant a I'Àfrica subsahariana, J. Muela n'ha estudiat els sincretismes mèdics a Tanzània (2000, 2002a,2002b,2003). Sobre el món àrab, J. LI. Mateo ha analitzat la relació de frontera i les relacions sociopolítiques entre Marroc i l'Estat espanyol en el període colonial durant el protectorat espanyol al Marroc (2003b), la política de repressió colonial referent a les unions mixtes entre dones espanyoles i homes marroquins (2003a), i la concepció espanyola d'aquestes unions en la literatura i l'administració colonials (2006), a més de la reacció local davant la colonització i la imatge de l'espanyol en l'imaginari marroquí, incloent les imatges sexuals, la idea del matrimoni i l'efecte de les mescles (2004). En el mateix sentit, les recerques de M. Ojeda Mata (2003, 2005, 2006) han obert la via per a comprendre la conceptualització dels sefardites considerats com a "espanyols jueus" en l'Espanya del segle XIX i plantejar així les contradiccions identitàries ambigües respecte d'aquesta comunitat; la qüestió és com pensadors espanyols enfoquen i tracten de recuperar als sefardites per 


\section{peripheria \\ vol.4, julio 2006 \\ www.periferia.name}

considerar-los espanyols jueus i com aquest procés influí en la postura del règim franquista davant dels refugiats jueus europeus durante la segona guerra mundial. Aquesta recerca sorgeix i ha estat precedida per una recerca més general sobre l'auge pararel del nacionalisme i l'antisemitsme a Europa i a Hongria durant la segona meitat del segle XIX i primera meitat del XX (2001). Així, des de finals dels anys noranta es produeix una part de la recerca que serà la base per al projecte vigent sobre identitats ambivalents.

\section{Mescles, identitats ambivalents: estudi comparatiu a Europa, Amèrica i Àfrica}

Aquest projecte, de tres anys de durada (2006-2008) ${ }^{2}$, té com a primer objectiu col-lectiu I'anàlisi, des d'una perspectiva històrica i antropològica, dels conceptes associats amb la noció de mestissatge, prenent especialment com a base les històries colonials europees des del segle XV a Amèrica i Àfrica, les històries nacionals i les ideologies nacionalistes europees, i el desenvolupament de les tradicions intel-lectuals que les han alimentat. I, paral-lelament, l'anàlisi de les categories intermèdies, de les identitats ambivalents, que amenacen les classificacions congelades, essencials, estàtiques des d'una perspectiva històrica, etnogràfica i antropològica; categories que ens permeten sortir de les definicions tradicionals de la identitat com a estratègia o com a essència: el rol de figures que apareixen en qualsevol situació de contacte, d'interaccions entre comunitats o col-lectius sociopolítics entesos com a diferents, de relacions interculturals o de situacions multiculturals, partint de la base que les diferències són sempre construïdes i que els "mestissos" no neixen sinó que es fan (cf. Stolcke 2004b); figures com les de comerciants, mercaders, cacics, conversos, missioners, xamans, emigrants, viatgers, mediadors culturals, líders, traductors, etc. Més que incorporar noves categories a les classificacions socials i ètniques tradicionals, es tracta d'incorporar en les anàlisis a personatges que estableixen ponts i construeixen en el camí noves relacions i realitats socials i culturals. En aquest apartat, la recerca combina les diferents tècniques antropològiques $\mathrm{i}$ historiogràfiques: treball de camp, amb observació participant, entrevistes en profunditat, històries de vida i buidat i anàlisi de documents d'arxius, a banda de documentació bibliogràfica.

\footnotetext{
${ }^{2}$ Aquest projecte, coordinat per Montserrat Ventura i Oller, ha rebut el Suport als Grups de Recerca de Catalunya (SGR) per a grups emergents en la convocatòria 2005 (2005SGR 00217).
} 


\section{peripheria \\ vol.4, julio 2006 \\ www.periferia.name}

Simultàniament, la recerca desenvolupa els objectius del projecte en àrees $\mathrm{i}$ realitats empíriques particulars, on, novament, el treball de camp, amb observació participant, entrevistes en profunditat, històries de vida i el buidat i anàlisi de documents d'arxius, tenen un paper clau. Així, els diferents membres de l'equip han realitzat, realitzen o realitzaran estades de camp a Equador, Panamà, Tanzània, Marroc, i recerca bibliogràfica i d'arxius a Washington, Londres, Madrid, Roma, Sevilla i Basilea.

Els primers avenços del projecte foren discutits en una trobada que tingué lloc el maig del 2005 en el marc del curs "elogi de la frontera: entre límits i ponts" organitzat per I'Institut Català de Cooperació amb Iberoamèrica, les aportacions del qual són en curs de publicació (cf. Lluís, A; G. Dalla-Corte, M. Ventura coords, en premsa), on es presentà una visió àmplia en el temps i la perspectiva teòrica entorn a la gènesi i el desenvolupament de la noció de mestissatge. En aquelles primeres propostes ja queda clara la necessitat d'anar més enllà de l'estudi de les fronteres ètniques per a comprendre les identitats indígenes, incorporant l'estudi de la noció de persona i d'humanitat, que no són universals, i que ens permeten copsar els límits de la possibilitat de les barreges i de la seva conceptualització pels pobles indígenes. Aquests, més que la humanitat, atorguen altres característiques a la socialitat i a la civilitat, com la capacitat de comunicació, i aquesta assumpció és fonamental per iniciar el veritable camí occidental de la comprensió de l'altre. També hi foren analitzades les figures pont, aquelles que transgredeixen les fronteres identitàries, com els nous líders indígenes o els mestissos i criolls al Perú virregnal dels segles XVI a XVIII, figures ambigües tant des de la perspectiva indígena com colonial i occidental, per la qual cosa són alhora objecte de desig i de rebuig.

L'equip segueix treballant en I'elaboració dels conceptes i I'anàlisi en les realitats particulars per assolir una perspectiva àmplia, comparativa, històrica i etnogràfica, teòrica i empírica, d'aquesta noció tan carregada semànticament i tan ambigua socialment com és la del mestissatge.

\section{Bibliografía citada}




\section{peripheria \\ vol.4, julio 2006 \\ www.periferia.name}

Clua, Montserrat (1998). Aproximació a les teories del nacionalisme des de I'antropologia", tesina de Màster dirigida pel Dr.Ramón Valdés del Toro, Bellaterra: UAB, n.p.

Clua, Montserrat (2003). "¿La extraña pareja? Antropología y nacionalismo", en González \& Molina (ed.): Abriendo surcos en la tierra. Bellaterra: Publicacions de la UAB, pp.275-286.

Coello de la Rosa, Alexandre (2000). El Barro de Cristo. Entre la Corona y el Evangelio en el Perú virreinal (1568-1581), Universitat Autònoma de Barcelona (U.A.B), Servei de Publicacions d'Antropologia Social, Bellaterra.

Coello de la Rosa, Alexandre (2002a). "Spaces of Exclusion, Spaces of Power in Colonial Lima, 1580-1592", a (Dis)Locating Modernity. Space and Subjectivity in Early Latin America, University of Arkansas Press.

Coello de la Rosa, Alexandre (2002b) "Representing the New World's Nature: Wonder and Exoticism in Gonzalo Fernández de Oviedo". Historical Reflections, Vol. $28, n^{\circ} 1$, Spring.

Coello de la Rosa, Alexandre (2003) "Apunts per a una biografia de l'extàtic i fervorós Pare Juan de Alloza de la Companyia de Jesús (1597-1666)". Afers. Fulls de Recerca i Pensament (Catarroja, Valencia) no 45 (Vol. XVIII), pp. 435-445.

Hausmann-Muela, S. \& Muela Ribera, J. (2000). Illness naming and home treatment practices for malaria - an example from Tanzania. In: Geissler, W. \& Meinert, L. (eds.) Proceedings of a workshop on "People and Medicines in East Africa" held in November 1998 in Mbale, Uganda, Danish Bilharziasis Laboratory $(\mathrm{dbl})$, Copenhagen

Hausmann-Muela, S., Muela Ribera, J., Mushi, A.K. \& Tanner, M (2002). Medical syncretism with reference to malaria in a Tanzanian community. Social Science and Medicine, 55(3), 403-413.

Hausmann-Muela, S. \& Muela Ribera, J. (2003). Recipe knowledge : a tool for understanding some apparently irrational behaviour. Anthropology \& Medicine, 10(1), 87-105.

Lluís, A; G. Dalla-Corte, M. Ventura coords (en premsa). Elogi de la frontera: entre límits $i$ ponts. Barcelona: Publicacions de I'Institut Català de Cooperació Iberoamericana.

Martínez Mauri, Mònica (2003). Médiation et développement.L'émergence des ONG et des passeurs culturels à Kuna Yala (Panamá). Collection Itinéraires No 16. Genève : Publications de l'IUED.

Martínez Mauri, Mònica (2005). "Indigenous Ngo And Cultural Mediators: una Yala (Panama) 1925-2004", World Public Forum "Dialogue of civilizations" Bulletin n०2/2005. 


\section{peripheria \\ vol.4, julio 2006 \\ www.periferia.name}

Martínez Mauri, Mònica (2006). "Entre Kuna Yala y Ginebra. La participación de las ONG indígenas en el sistema de las Naciones Unidas " in Laura Mameli i Eleonora Muntañola (eds) America Latina: Realidades Diversas.

Barcelona: ICCI-Casa de América, Colección Amer\&Cat 13.

Martínez Mauri, Mònica (en premsa) "Puentes en las fronteras:

identidad y mediadores culturales kunas" in A. Lluis, G. Dalla-Corte, M. Ventura (coords) Elogi de la frontera: entre límits $i$ ponts. Barcelona: Publicacions de I'Institut Català de Cooperació Iberoamericana.

Martinez-Alier, Verena (1974). Marriage, Class and Colour in Nineteenth Century Cuba. Cambridge University Press, 1974 (re-editat per Michigan University Press el 1989 i 2003), publicat en castellà sota el títol Sexualidad y Racismo en la Cuba Colonial. Madrid: Alianza Editorial 1992).

Mateo Dieste, Josep Lluís (2003a). La 'hermandad' hispano-marroquí. Política y religión bajo el Protectorado español en Marruecos (1912-1956), Barcelona: Edicions Bellaterra.

Mateo Dieste, Josep Lluís (2003b). "Pourquoi tu ne m'écris plus?" Les rapports mixtes et les frontières sociales dans le Protectorat Espagnol au Maroc", Hawwa. Journal of Women in North Africa and the Middle East, 1:2, pp. 241-268.

Mateo Dieste, Josep Lluís (2004): "De los 'remendados' al Hajj Franco: los españoles en el imaginario colonial marroquí", Illes i Imperis, no 7, pp. 63-92.

Mateo Dieste, Josep Lluís (2006). "Amores prohibidos. Fronteras sexuales y uniones mixtas en el Marruecos colonial", en Ana Planet (ed.), Marruecos y España. Una vecindad en construcción, Madrid, Ediciones del Oriente y del Mediterráneo, pp. 128-159.

Muela Ribera, J. \& Hausmann-Muela, S. (2002). La medicina tradicional en los programas de la OMS. En: Abriendo surcos en la tierra. Investigación básica y aplicada en la UAB. Homenaje a Ramón Valdés, González Echevarría, A. \& Molina, J.L. (Coord.), Publicacions d'Antropologia Cultural, Universitat Autònoma de Barcelona.

Ojeda Mata, Maite (2001) «Assimilation et différence: les Juifs et l'ètat-nation hongrois, 1895-1914 », Les limites des siècles II, pp.339-248.

Ojeda Mata, Maite (2003). ''Spanish and Jewish?' A Historical Anthropological Approach to Franco's Spain and the Shoah", Windows on a Jewish World, pp.15-23.

Ojeda Mata, Maite (2005). "Thinking about 'the Jew' in Modern Spain: Nineteenth and Early Twentieth-Century Spanish Historiography and its Impact in Franco's Spain", Jewish Culture and History, Vol. 8 (en premsa).

Ojeda Mata, Maite (2006). «Le Protectorat Espagnol du Maroc et les Juifs et Juives », a Le Tiers, Paris (en premsa). 


\section{peripheria \\ vol.4, julio 2006 \\ www.periferia.name}

Stolcke, Verena (1986). Cafeicultura: Homens, Mulheres e Capital (1850-1980). Sao Paulo : Ed. Brasiliense S.A. (publicat en anglès sota el títol Coffee Planters, Workers and Wives: Class Conflict and Gender Relations on Sao Paulo Coffee Plantations, 1850-1980. Oxford: St. Antony's College/Macmillan, 1988.

Stolcke, Verena (1988). "New reproductive technologies - old fatherhood". Reproductive and Genetic Engineering 1 (1).

Stolcke, Verena (1995). "Talking culture. New boundaries, new rhetorics of exclusion in Europe (The Sidney Mintz Lecture, Johns Hopkins University), Current Anthropology 36 (1) febrer.

Stolcke, Verena (1997). "The 'nature' of nationality". Bader, V. (ed.). Citizenship and exclusion. Londres: Macmillan Press Ltd.,

Stolcke, Verena (1998a). "El sexo de la biotecnología". Riechmann, J. y A. Durán (eds). Genes en el laboratorio y en la fábrica. Madrid: Editorial Trotta/Fundación 1 ero de Mayo.

Stolcke, Verena (1998b). "Brasil: una nación vista a través del cristal de la 'raza'". Revista de Cultura Brasileña, Madrid, no.1, marzo.

Stolcke, Verena (2000a). "Cultural Fundamentalism", UNESCO, World Culture Report 2000. Cultural Diversity, Conflict and Pluralism, Paris: UNESCO.

Stolcke, Verena (2000b), "Cuando el racismo se convierte en pantalla de la explotación", S.O.S. Racismo, Informe Anual 2000 sobre el racismo en el estado español, , Barcelona: Icaria Editorial.

Stolcke, Verena. (2002), "Dialéctica de género en el trabajo en las plantaciones de café - Sao Paulo, Brasil", R. Piqué \& M. Ventura (eds), América Latina. Historia y Sociedad. Una Visión Interdisciplinaria (Cinco años de Aula Oberta en la UAB), Barcelona: ICCI / UAB.

Stolcke, Verena (2003a), "La mujer es puro cuento: la cultura del género", Quaderns de l'Institut Cátala d'Antropología, serie monográfica: A propósito de cultura, coordinado por Stolcke, V., no. 19.

Stolcke, Verena (2003b), "La influencia de la esclavitud en la estructura doméstica y la familia en Jamaica, Cuba y Brasil", Desacatos. Revista de Antropología Social, CIESAS México, no. 13, invierno 2003.

Stolcke, Verena (2004a), "Qué entendemos por integración social de los inmigrantes", F. Checa, J.C. Checa y A. Arjona (eds), Inmigración y derechos humanos. La integración como participación social, Barcelona: Icaria Editorial.

Stolcke, Verena (2004b), "A New World Engendered. The Making of the Iberian Transatlantic Empire", T.A. Meade \& M.E. Wiesner-Hanks (eds), A Companion to Gender History, Serie: Blackwell Companions to History, Oxford: Blackwell Publishing. 


\section{peripheria}

vol.4, julio 2006

www.periferia.name

Ventura i Oller, Montserrat (1994). "Etnicitat i racisme". Revista d'Etnologia de Catalunya, n.5, pp.116-133.

Ventura i Oller, Montserrat (1995). "En el camino. Los Tsachila en el complejo étnico de la selva occidental del Ecuador" in Alvarez, A. et al (eds) Primer encuentro de investigadores de la costa ecuatoriana en Europa, Quito: Abya-Yala, pp.433-465.

Ventura i Oller, Montserrat (1997). "Una visión de la cultura Tsachila en la actualidad", in José E. Juncosa (ed) Etnografías mínimas del Ecuador, Quito: AbyaYala, pp.1-32.

Ventura i Oller, Montserrat (1999a). ««Ser Tsáchila en el Ecuador Contemporáneo. Un análisis desde la antropología », Ecuador Debate, no 48, Quito, diciembre, pp.95118.

Ventura i Oller, Montserrat (1999b). «Langue, mythes, chamanisme - une vieille histoire: représentations du passé et du contact interethnique dans l'occident équatorien », Bulletin de la Société Suisse des Américanistes, no 63, pp.63-70.

Ventura i Oller, Montserrat (2000a). À la croisée des chemins. Identité, rapports à autrui et chamanisme chez les Tsachila de l'Équateur, Thèse Doctorale, École des Hautes Études en Sciences Sociales, Paris.

Ventura i Oller, Montserrat (2000b). « Several representations, internal diversity, one singular people », Social Anthropology, 8, 1, pp.61-67.

Ventura i Oller, Montserrat (2001). «El cos com a frontera en un ritual col.lectiu Tsachila », Revista d'Etnologia de Catalunya, núm. 18, Abril, pp.8-15.

Ventura i Oller, Montserrat (2002). "Verdades relativas. Reflexiones entorno a la comprensión del mundo. El caso tsachila del Ecuador", in J. Bestard Camps (comp) Identidades, relaciones y contextos, Barcelona: Dept. d'Antropologia i d'Història d'Amèrica i Àfrica, Universitat de Barcelona, pp.115-128.

Ventura i Oller, Montserrat (2003). "Schamanische Austauschbeziehungen und Identität. Das Netzwerk der Colorados", in Dagmar Schweitzer de Palacios \& Bernhard Wörrle (eds) Heiler zwischen den welten. Transkulturelle Austauschprozesse im Schamanismus Ecuadors, Marburg/Lahn: Curupira, pp. 7395.

Ventura i Oller, Montserrat (2004). "Sendas de unión entre mundos" in A. Surrallés y P. García Hierro (eds) Tierra Adentro, territorio indígena y percepción del entorno, Copenhague: IWGIA. 